\title{
Updates in postural tachycardia syndrome
}

\author{
Jangsup Moon ${ }^{1,2}$ \\ 'Department of Neurology, Seoul National University Hospital, Seoul, Korea \\ ${ }^{2}$ Rare Disease Center, Department of Genomic Medicine, Seoul National University Hospital, Seoul, Korea
}

Received: January 20, 2021

Revised: February 18, 2021

Accepted: February 19, 2021

Postural tachycardia syndrome (POTS) is the most common form of orthostatic intolerance in young people. However, it is still considered an underrecognized disorder and so deserves more attention from clinicians. This review covers the diagnostic challenges, correlations between the symptoms, evidence of autoimmune involvement in the pathogenesis, and treatment strategies in POTS.

Key words: Postural orthostatic tachycardia syndrome; Diagnosis; Symptoms; Autoimmunity; Treatment

\section{Correspondence to}

Jangsup Moon

Department of Neurology, Seoul National University Hospital, 101 Daehak-ro, Jongno-gu, Seoul 03080, Korea

Tel: $+82-2-2072-4265$

Fax: $+82-2-765-7920$

E-mail:jangsup.moon@gmail.com

ORCID

Jangsup Moon

https://orcid.org/0000-0003-1282-4528

\section{INTRODUCTION}

Postural tachycardia syndrome (POTS) is a common cause of orthostatic intolerance that is characterized by an excessive increase in heart rate (HR) upon standing. ${ }^{1,2}$ POTS not only causes the well-recognized symptoms of dizziness and palpitation, but also various other symptoms including headache, fatigue, profuse perspiration, blurred vision, difficulty concentrating, and gastrointestinal discomfort. ${ }^{3,4}$ The clinical significance of POTS has recently increased with findings of associations with depression, ${ }^{5,6}$ sleep disturbance, ${ }^{7}$ chronic fatigue syndrome, ${ }^{8-10}$ and diminished quality of life $(\mathrm{QOL}){ }^{7,11}$ Despite the increased prevalence of POTS reported over the past 2 decades due to the increased awareness of this syndrome, ${ }^{1}$ it is still considered an underdiagnosed disease and deserves more attention from clinicians. ${ }^{4,12}$

\section{DIAGNOSTIC CHALLENGES: MULTIPLE PHENOTYPES AND DIURNAL VARIABILITY}

POTS can be diagnosed in patients with orthostatic intolerance symptoms when the fol- 
lowing criteria are fulfilled: HR increment of $\geq 30$ beats/min (or $\geq 40$ beats/min in individuals aged 12-19 years) within 10 minutes of standing or head-up tilting, and in the absence of orthostatic hypotension (a decrease in systolic blood pressure [BP] of $\geq 20 \mathrm{mmHg}$ and/or decrease in diastolic BP of $\geq 10 \mathrm{mmHg}$ ) and other causes of tachycardia. ${ }^{13,14}$ However, there are challenges associated with diagnosing POTS. For example, patients often present with various symptoms other than the typical ones of dizziness and palpitations, which may obscure an accurate diagnosis. ${ }^{1}$ Many POTS patients complain of headache, depression, fatigue, difficulty concentrating, and gastrointestinal disturbances such as abdominal pain and irregular bowel movements. ${ }^{12,15}$ Therefore, an accurate POTS diagnosis requires a detailed knowledge of the history of the patient's symptoms.

Many patients also complain of worsening of symptoms in the morning with subsequent improvement throughout the course of the day, which may be explained by the diurnal variability of hemodynamic parameters. ${ }^{16}$ It has been demonstrated that orthostatic HR increments are greater in the morning than in the afternoon, and so some patients may fulfill the criteria for POTS in the morning but not later in the day. ${ }^{17}$ This discrepancy is probably due to the physiological changes that occur during sleep associated with being supine for a prolonged period without any fluid intake.' Therefore, when there is clinical suspicion of POTS, repeated orthostatic vital-sign tests should be conducted, including one in the early morning.

\section{ORTHOSTATIC INTOLERANCE SYMPTOMS IN POTS}

Orthostatic intolerance is the main characteristic of POTS, ${ }^{15}$ and can manifest as a variety of symptoms such as headache, dizziness, nausea, lightheadedness, blurred vision, palpitations, tremors, and difficulty concentrating. ${ }^{4,15}$ It has been reported that the degree of orthostatic HR increment is not directly correlated with clinical symptoms, probably due to the diurnal variability of orthostatic tachycardia. ${ }^{3}$ However, the severity of orthostatic intolerance symptoms is significantly correlated with depression and QOL. In particular, chest discomfort and difficulty concentrating are strongly associated with depression, and nausea and difficulty concentrating are associated with diminished QOL. ${ }^{3}$

\section{EVIDENCE FOR AUTOIMMUNITY}

The exact pathogenesis underlying POTS remains unknown. Several clinical characteristics support the possibility that POTS is an autoimmune disorder, such as female predominance, preceding viral illness, prior vaccination history, and coexistence of other autoimmune disorders, characteristics that are frequently reported in other autoimmune diseases. $^{18}$

There have been many reports describing patients who developed POTS after receiving a polyvalent human papilloma virus (HPV) vaccine. ${ }^{19-24}$ However, the American Autonomic Society recently issued a statement concluding that the available evidence was insufficient to confirm a causal relationship between receipt of an HPV vaccination and development of POTS. ${ }^{25}$

The presence of various types of autoantibody in patients with POTS and their effects on cholinergic and adrenergic receptors has been found in numerous studies. ${ }^{26,27}$ While the presence of antibodies to ganglionic acetylcholine receptors (AChRs) has both low sensitivity and specificity for a POTS diagnosis, antibodies to adrenergic receptors are likely to be involved in the pathogenesis and can be used as a potential diagnostic biomarker. ${ }^{28}$ One group found that most patients with POTS harbored antibodies that activate the $\beta 1$ adrenergic receptor, while a smaller proportion of patients had antibodies that activate the $\beta 2$ adrenergic receptor and also act as partial agonists/antagonists to a1 receptors. ${ }^{18,27}$ Moreover, patients with POTS have a higher positive rate of antinuclear antibodies than general population, ${ }^{29}$ as well as a higher incidence of systemic autoimmune disease, including Hashimoto's thyroiditis, Sjögren's syndrome, lupus, and rheumatoid arthritis. ${ }^{28}$ Therefore, it has been suggested that POTS should be considered a novel member of the family of autoimmune disorders. ${ }^{25}$

An association with human leukocyte antigen allele status was recently reported in Korean patients with severe POTS, defined as an orthostatic HR increment of $\geq 50$ beats/min or experiencing syncope/near-syncope during orthostatic vital-signs measurement. ${ }^{30}$ Seven of 17 patients (41\%) harbored $D Q B 1^{*} 06: 09$ and six (35\%) had the $A * 33: 03-B * 58: 01$ - 
$C * 03: 02-D R B 1^{*} 13: 02-D Q B 1 * 06: 09$ haplotype, a significantly higher proportion than was found among healthy Koreans (Table 1). ${ }^{30}$

Based on these findings, at least a proportion of POTS cases should be considered autoimmune in nature. The development of the first animal model of POTS, achieved by immunization of rabbits with adrenergic receptor peptides, ${ }^{31}$ promises to be useful for future mechanistic studies. These animals exhibit POTS-like phenotypes in vivo, such as orthostatic tachycardia. ${ }^{32}$

\section{TREATMENT}

\section{Nonpharmacological management}

Many nonpharmacological therapies are available for the treatment of POTS, ${ }^{33}$ among which lifestyle modification and exercise are the two mainstays. Drinking $500 \mathrm{~mL}$ of

\section{Table 1. Evidence for an autoimmune component in POTS}

\section{Evidence supporting autoimmunity in POTS}

Female predominance

History of preceding viral infection

HLA associations: DQB1*0609

(A*3303-B*5801-C*0302-DRB1*1302-DQB1*0609 haplotype)

Autoantibodies: antiadrenergic receptor Abs, anti-AChR Abs (increased prevalence of antiphospholipid Abs, antinuclear Abs)

Response to immunotherapy: demonstrated in small case-series studies (warrants further investigation)

POTS, postural tachycardia syndrome; HLA, human leukocyte antigen; Abs, antibodies; AChR, acetylcholine receptor. water quickly before getting out of bed in the morning or before prolonged standing is recommended, while standing up abruptly from a sitting or recumbent position should be avoided. A leg-crossing maneuver is a practical measure that can be used when patients encounter situations that require a prolonged upright posture. It is also important to avoid situations that can exacerbate symptoms, including heat exposure, consuming a large meal, and drinking alcohol.'

Exercise is an essential part of POTS treatment, ${ }^{34}$ with isometric exercises and squatting being particularly beneficial. ${ }^{35}$ Isometric exercises involve contracting muscles without moving the body, such as the leg-pillow squeeze or arm-pillow squeeze, acting to compress the muscles and push the blood back toward the heart. These are simple exercises that can be done at any time while sitting in a chair or lying in a bed. Reclined aerobic exercise, such as swimming or recumbent bicycling, is also highly beneficial. ${ }^{36}$

The major challenge of nonpharmacological treatment is the achievement of regular and consistent patient compliance for at least 3 months. ${ }^{1,37}$ Some patients will complain that they feel more fatigued during the first week of exercise, which may lead to them stopping the exercise program.

\section{Pharmacological treatments}

Given the low compliance with exercise interventions, pharmacological treatment should be initiated early in POTS patients. The symptoms of POTS are known to worsen in a vicious cycle. They may develop in susceptible individuals after certain triggering events such as infection, concussion, and enforced bedrest. Orthostatic intolerance in these patients consequently leads to diminished activity, cardiovascular deconditioning, and worsening of symptoms. ${ }^{1}$ It is

Table 2. Pharmacological treatments for POTS

\begin{tabular}{lcc}
\hline Drug & Dosing information & Side effects \\
\hline Propranolol & $10-20 \mathrm{mg}$ up to four times daily & Hypotension, bradycardia, bronchospasm \\
Bisoprolol & $2.5-5 \mathrm{mg}$ daily & Headache, bradycardia, nausea \\
Pyridostigmine & $30-60 \mathrm{mg}$ up to three times daily & Diarrhea, vomiting, abdominal cramps \\
Midodrine & $2.5-15 \mathrm{mg}$ three times daily & Headache, supine hypertension \\
Fludrocortisone & $0.1-0.2 \mathrm{mg}$ daily & Hypokalemia, edema, headache \\
Desmopressin & $0.1-0.2 \mathrm{mg}$ as needed & Hyponatremia, edema \\
Droxidopa & $100-600 \mathrm{mg}$ three times daily & Headache, nausea, hypertension, tachycardia \\
\hline
\end{tabular}

POTS, postural tachycardia syndrome. 
important to break this vicious cycle as soon as possible after the diagnosis, using both nonpharmacological and pharmacological approaches.

The United States Food and Drug Administration has not yet approved any medications for POTS, but there are several agents that could be beneficial. Numerous studies have shown that beta-blockers such as propranolol ${ }^{38}$ and bisoprolol, ${ }^{39}$ the AChR inhibitor pyridostigmine, ${ }^{40}$ the antihypotensive midodrine, ${ }^{41}$ and the steroid fludrocortisone ${ }^{39}$ and others are effective treatments for POTS (Table $2{ }^{4}{ }^{42}$ Several randomized trials have demonstrated the efficacy of propranolol, pyridostigmine, and midodrine for improving orthostatic tachycardia; however, most of the drug trials for these agents were designed to evaluate only the acute response (i.e., 2-4 hours after administration). ${ }^{38,40,41}$ Few studies have investigated the sustained effects of daily medical treatments. ${ }^{43,44}$

My group recently demonstrated that four different treatment protocols consisting of propranolol or bisoprolol with or without pyridostigmine for 3 months were effective for improving orthostatic intolerance symptoms in patients with POTS. ${ }^{43}$ A remarkable finding of this work is that 3 months of this medical treatment was also effective for improving symptoms of depression and diminished QOL, even without concomitant administration of antidepressants.

Given the potential involvement of autoimmune mechanisms in POTS, it is possible that immunotherapy can help improve the symptoms, or at least in a specific subgroup of patients. The efficacy of immunotherapies, including steroid pulse and intravenous immunoglobulin treatment, has yet to be established and warrants further investigation.

In summary, pharmacological treatment is an important part of the management of POTS, and is especially useful for the early improvement of symptoms when applied in combination with nonpharmacological management. After 3 months of combined treatment, medications can be reduced or maintained depending on the patient's persisting symptoms.

\section{CONCLUSION}

POTS is a heterogeneous clinical syndrome that causes chronic orthostatic intolerance and is accompanied by other medical conditions. It is important to understand that diurnal variability of hemodynamic parameters exists and that the symptoms of orthostatic intolerance are associated with depression and diminished QOL. The pathophysiology of POTS is not fully understood, but an autoimmune component has recently been proposed. An integrative approach combining nonpharmacological and pharmacological treatments is important for the management of this condition.

\section{Conflicts of Interest}

The authors declare no conflicts of interest relevant to this article.

\section{REFERENCES}

1. Bryarly M, Phillips LT, Fu Q, Vernino S, Levine BD. Postural orthostatic tachycardia syndrome: JACC focus seminar. J Am Coll Cardiol 2019;73:1207-1228.

2. Mathias CJ, Low DA, lodice V, Owens AP, Kirbis M, Grahame R. Postural tachycardia syndrome-current experience and concepts. Nat Rev Neurol 2011;8:22-34.

3. Moon J, Kim DY, Byun JI, Sunwoo JS, Lim JA, Kim TJ, et al. Orthostatic intolerance symptoms are associated with depression and diminished quality of life in patients with postural tachycardia syndrome. Health Qual Life Outcomes 2016;14:144.

4. Pandian JD, Dalton K, Henderson RD, McCombe PA. Postural orthostatic tachycardia syndrome: an underrecognized disorder. Intern Med J 2007;37:529-535.

5. Lkhagvasuren B, Oka T, Kawai K, Takii M, Kanemitsu Y, Tokunaga $S$, et al. Prevalence of postural orthostatic tachycardia syndrome in patients with psychiatric disorders. Psychother Psychosom 2011;80:308-309.

6. Benarroch EE. Postural tachycardia syndrome: a heterogeneous and multifactorial disorder. Mayo Clin Proc 2012;87:1214-1225.

7. Bagai K, Song Y, Ling JF, Malow B, Black BK, Biaggioni I, et al. Sleep disturbances and diminished quality of life in postural tachycardia syndrome. J Clin Sleep Med 2011;7:204-210.

8. Reynolds GK, Lewis DP, Richardson AM, Lidbury BA. Comorbidity of postural orthostatic tachycardia syndrome and chronic fatigue syndrome in an Australian cohort. J Intern Med 2014;275:409417.

9. Lewis I, Pairman J, Spickett G, Newton JL. Clinical characteristics of a novel subgroup of chronic fatigue syndrome patients 
with postural orthostatic tachycardia syndrome. J Intern Med 2013;273:501-510.

10. Karas B, Grubb BP, Boehm K, Kip K. The postural orthostatic tachycardia syndrome: a potentially treatable cause of chronic fatigue, exercise intolerance, and cognitive impairment in adolescents. Pacing Clin Electrophysiol 2000;23:344-351.

11. Benrud-Larson LM, Dewar MS, Sandroni P, Rummans TA, Haythornthwaite JA, Low PA. Quality of life in patients with postural tachycardia syndrome. Mayo Clin Proc 2002;77:531-537.

12. Schmidt LL, Karabin BL, Malone AC. Postural orthostatic tachycardia syndrome (POTS): assess, diagnose, and evaluate for POTS treatment (ADEPT). Integr Med Int 2017;4:142-153.

13. Sheldon RS, Grubb BP 2nd, Olshansky B, Shen WK, Calkins H, Brignole $\mathrm{M}$, et al. 2015 heart rhythm society expert consensus statement on the diagnosis and treatment of postural tachycardia syndrome, inappropriate sinus tachycardia, and vasovagal syncope. Heart Rhythm 2015;12:e41-e63.

14. Freeman R, Wieling W, Axelrod FB, Benditt DG, Benarroch E, Biaggioni I, et al. Consensus statement on the definition of orthostatic hypotension, neurally mediated syncope and the postural tachycardia syndrome. Clin Auton Res 2011;21:69-72.

15. Garland EM, Celedonio JE, Raj SR. Postural tachycardia syndrome: beyond orthostatic intolerance. Curr Neurol Neurosci Rep 2015 Jul 22. [Epub]. DOl:10.1007/s11910-015-0583-8.

16. Brewster JA, Garland EM, Biaggioni I, Black BK, Ling JF, Shibao CA, et al. Diurnal variability in orthostatic tachycardia: implications for the postural tachycardia syndrome. Clin Sci (Lond) 2012;122:2531.

17. Moon J, Lee HS, Byun JI, Sunwoo JS, Shin JW, Lim JA, et al. The complexity of diagnosing postural orthostatic tachycardia syndrome: influence of the diurnal variability. J Am Soc Hypertens 2016;10:263-270.

18. Li H, Yu X, Liles C, Khan M, Vanderlinde-Wood M, Galloway A, et al. Autoimmune basis for postural tachycardia syndrome. J Am Heart Assoc 2014;3:e000755.

19. Blitshteyn S, Brook J. Postural tachycardia syndrome (POTS) with anti-NMDA receptor antibodies after human papillomavirus vaccination. Immunol Res 2017;65:282-284.

20. Brinth L, Theibel AC, Pors K, Mehlsen J. Suspected side effects to the quadrivalent human papilloma vaccine. Dan Med J 2015;62:A5064.

21. Brinth LS, Pors K, Theibel AC, Mehlsen J. Orthostatic intolerance and postural tachycardia syndrome as suspected adverse effects of vaccination against human papilloma virus. Vaccine
2015;33:2602-2605

22. Blitshteyn S. Postural tachycardia syndrome after vaccination with Gardasil. Eur J Neurol 2010;17:e52.

23. Blitshteyn S. Postural tachycardia syndrome following human papillomavirus vaccination. Eur J Neurol 2014;21:135-139.

24. Kinoshita T, Abe RT, Hineno A, Tsunekawa K, Nakane S, Ikeda S. Peripheral sympathetic nerve dysfunction in adolescent Japanese girls following immunization with the human papillomavirus vaccine. Intern Med 2014;53:2185-2200.

25. Dahan S, Tomljenovic L, Shoenfeld Y. Postural orthostatic tachycardia syndrome (POTS)-a novel member of the autoimmune family. Lupus 2016;25:339-342.

26. Ruzieh M, Batizy L, Dasa O, Oostra C, Grubb B. The role of autoantibodies in the syndromes of orthostatic intolerance: a systematic review. Scand Cardiovasc J 2017;51:243-247.

27. Fedorowski A, Li H, Yu X, Koelsch KA, Harris VM, Liles C, et al. Antiadrenergic autoimmunity in postural tachycardia syndrome. Europace 2017;19:1211-1219.

28. Vernino S, Stiles LE. Autoimmunity in postural orthostatic tachycardia syndrome: current understanding. Auton Neurosci 2018;215:78-82.

29. Blitshteyn S. Autoimmune markers and autoimmune disorders in patients with postural tachycardia syndrome (POTS). Lupus 2015;24:1364-1369.

30. Shin YW, Moon J, Kim TJ, Kim DY, Chang H, Jun JS, et al. Human leukocyte antigen associations in postural tachycardia syndrome. Ann Clin Transl Neurol 2019;6:962-967.

31. Li H, Zhang G, Zhou L, Nuss Z, Beel M, Hines B, et al. Adrenergic autoantibody-induced postural tachycardia syndrome in rabbits. J Am Heart Assoc 2019;8:e013006.

32. Miller AJ, Doherty TA. Hop to it: The first animal model of autoimmune postural orthostatic tachycardia syndrome. J Am Heart Assoc 2019;8:e014084.

33. Zhang $Q, X u B, D u$ J. Update of individualized treatment strategies for postural orthostatic tachycardia syndrome in children. Front Neurol 2020;11:525.

34. Joyner MJ. Exercise training in postural orthostatic tachycardia syndrome: blocking the urge to block $\beta$-receptors? Hypertension 2011;58:136-137.

35. Wieling W, Colman N, Krediet CP, Freeman R. Nonpharmacological treatment of reflex syncope. Clin Auton Res 2004;14 Suppl 1:i62-i70.

36. Grubb BP. Postural tachycardia syndrome. Circulation 2008;117:2814-2817. 
37. Sousa A, Lebreiro A, Freitas J, Maciel MJ. Long-term follow-up of patients with postural tachycardia syndrome. Clin Auton Res 2012;22:151-153.

38. Raj SR, Black BK, Biaggioni I, Paranjape SY, Ramirez M, Dupont $W D$, et al. Propranolol decreases tachycardia and improves symptoms in the postural tachycardia syndrome less is more. Circulation 2009;120:725-734.

39. Freitas J, Santos R, Azevedo E, Costa O, Carvalho M, de Freitas AF. Clinical improvement in patients with orthostatic intolerance after treatment with bisoprolol and fludrocortisone. Clin Auton Res 2000;10:293-299.

40. Kanjwal K, Karabin B, Sheikh M, Elmer L, Kanjwal Y, Saeed B, et al. Pyridostigmine in the treatment of postural orthostatic tachycardia: a single-center experience. Pacing Clin Electrophysiol
2011;34:750-755.

41. Hoeldtke RD, Bryner KD, Hoeldtke ME, Hobbs G. Treatment of postural tachycardia syndrome: a comparison of octreotide and midodrine. Clin Auton Res 2006;16:390-395.

42. Miller AJ, Raj SR. Pharmacotherapy for postural tachycardia syndrome. Auton Neurosci 2018;215:28-36.

43. Moon J, Kim DY, Lee WJ, Lee HS, Lim JA, Kim TJ, et al. Efficacy of propranolol, bisoprolol, and pyridostigmine for postural tachycardia syndrome: a randomized clinical trial. Neurotherapeutics 2018;15:785-795.

44. Chen L, Wang L, Sun J, Qin J, Tang C, Jin H, et al. Midodrine hydrochloride is effective in the treatment of children with postural orthostatic tachycardia syndrome. Circ J 2011;75:927-931. 